\title{
Science A\&I Database Holdings at ARL and Oberlin Group Libraries, 2011-2016: A Longitudinal Study
}

\section{Timothy W. Klassen}

\begin{abstract}
After instituting major cuts to discipline-specific science abstracting and indexing (A\&l) databases at an ARL library due to significant budget cuts, the author sought to determine if such cuts were being made by other academic libraries and what trends could be found in holdings of such databases. Annually, over the course of eight years, 108 ARL libraries and 74 Oberlin Group library website A-Z database lists were reviewed to look for the presence of 21 Science and Technology A\&l databases. Additions and cancellations were recorded and verified. The results indicate little change in the holdings of several discipline-specific databases including MathsciNet, SciFinder Scholar, and GeoRef, while there were declines in holdings of several other databases including INSPEC, Biological Abstracts, and Compendex. Also measured were holdings of Proquest and EBSCO science A\&I databases, which saw small declines in holdings, as well as holdings of comprehensive A\&l databases Scopus and Web of Science, which saw a significant increase for Scopus holdings.
\end{abstract}

\section{Introduction}

The ongoing serials cancellation crisis has been a fact of life for collections managers since the $1980 \mathrm{~s}^{1}$ and, with the recent 2008 financial crisis and ongoing challenges for public higher education budgets, promises to be around for the foreseeable future. This study of science database holdings originated in 2010 when collections managers at the author's library were faced with a significant collections cut. The physical sciences and engineering collections manager, the author, and the life science collections manager were required to make these cuts in serials lines, which included individual journals subscriptions, society- and discipline-based publisher packages, and discipline-based bibliographic databases (often referred to as abstracting and indexing databases (A\&I)). Excluded were the big deals and cross-disciplinary publisher packages and databases. Due to these restrictions, the options were to either make very dramatic cuts in the number of individual journals subscriptions, already small in number after many years of cuts and publisher consolidation, or consider the discipline-specific databases and subject/society-based journal packages. After analyzing usage statistics and user consultation, including surveying faculty preferences for cutting databases versus substantial numbers of

\footnotetext{
*Timothy W. Klassen is Head, Science and Technology Library and Winspear Business Library at the University of Alberta, email: twklasse@ualberta.ca. @2020 Timothy W. Klassen, Attribution-NonCommercial (http://creativecommons.org/licenses/by-nc/4.0/) CC BY-NC.
} 
journals, the collection managers both choose to concentrate on databases rather than serials to achieve the financial targets; the library cancelled BIOSIS, Environmental Sciences and Pollution Abstracts, and INSPEC effective 2011.

Making such dramatic cuts in what would be considered core science databases came with great unease on the part of the author, after 18 years of experience in Science Librarianship at the time, and led to a great deal of reflection on the importance of these non-full-text A\&I databases in libraries and science research. It should be noted that there was no faculty outcry to either the potential loss of these resources or to the actual loss. Questions began to emerge including:

- Were other libraries facing tradeoffs of cutting journals versus databases making decisions similar to ours?

- Which, if any, science databases are most likely to be cancelled?

- Would some libraries subscribe to the comprehensive science databases Web of Science (WoS) and/or Scopus while canceling individual subject-oriented databases?

- Were libraries still subscribing to the three EBSCO science databases, formerly known as the Wilson Indexes (Applied Science and Technology Index, Biology and Agriculture Index, and General Science Index) now that much larger comprehensive science databases were available?

Answers to these questions and more would require comparison of the science A\&I database holdings of other libraries to determine what their holdings were and what was happening to these holdings over time. While making such comparisons for a number of libraries is labor intensive, compared to science serials, there are relatively few core science A\&I databases; and, with publicly accessible database A-Z lists being a nearly universal feature of academic library websites, it is relatively easy, although time consuming, to perform a census of holdings. The author reviewed 108 Association of Research Libraries (ARL) and 74 Oberlin Group library websites from 2010 through 2017 for evidence of subscriptions to 21 Science and Technology discipline-specific, intradisciplinary (in other words, one specific aspect of a discipline), and multidisciplinary A\&I databases. Native full-text databases such as IEEE and ACM were excluded, although some databases with partial full text (such as the former EBSCO science databases) were included. Although the results of such a census do not answer all of these questions, in particular why specific databases are cancelled on an individual basis, it does indicate which databases are being cancelled and allows for the possibility of discerning trends both in the specific databases and types of databases that are being cancelled or added.

\section{Literature Review}

There is an extensive literature on the serials crisis and cancellation policies and procedures. As Chadwell states, "the serials crisis has been with libraries, specifically academic libraries, on a large scale since the late [1980s], though there are libraries that made significant cuts in the mid and early 1980s." ${ }^{2}$ An early example of this literature is the 1985 article by Williamson $^{3}$ on cancellations at Georgia Tech, where she discusses the beginnings of the serials crisis, methods for determining cancellations, and the effects of these cancellations; she also mentions cancellations of print indexes in favour of online equivalents. In 1993, Chrzastowski and Schmidt ${ }^{4}$ reviewed serial expenditures versus number of serials received from 1987/88 through 1989/90 at 5 ARL schools, all members of the Midwest Committee on Institutional 
Cooperation library consortium, to provide a profile of at-risk journals and insights on cancellation policies. They followed up this study in $1996^{5}$ and determined that cancellations had accelerated and that science material was most at risk. In a $1997^{6}$ follow-up to this research, this time expanding to 10 academic libraries and looking at the years 1992-1994, they again found that science material was at most risk of cancellation. In her $1997^{7}$ article on trends in Academic Chemistry Serials Collections from 1992 to 1994, Chrzastowski found significant cuts in the science periodical literature and in chemistry in particular. To this day, there continues to be a rich literature on the serials crisis, cuts, cancellation policies, and methods used.

Though there is a small body of literature on cutting bibliographic databases, it is less rich than that for serials and until recently didn't directly address the sciences. However, following the advent in 2004 of both Google Scholar (GS) and Elsevier's SCOPUS, and the 2008 global financial crisis and associated higher education library budget forecasts (for example, Oder's ${ }^{8} 2009$ ARL Budget Roundup), several opinion pieces appeared prophesying upcoming cancellations for Science A\&I databases. In 2009, Wagner" speculated that, like paid "news," the day of costly abstracting and indexing databases was coming to an end due to the following circumstances: the ease of use of free subject-oriented databases and GS as well as other web search engines; preservation of journal subscriptions over A\&I in cancellation projects; low patron use statistics; overlap in content between niche databases; more comprehensive added value databases such as Scopus and WoS; and increasingly comprehensive full-text databases from EBSCO (Proquest should also be considered here). Wagner even speculated that, if GS could up its game on the value-added features of the top A\&I databases (for example, bibliometrics or chemical structures), then even the high added value databases might face cancellation. Tucci ${ }^{10}$ continued the discussion in 2010, proposing specifically that physical science and engineering databases are in a "death spiral." Tucci agreed with Wagner on reasons for the possible demise of A\&I databases, speculating that ease of use of free resources and their overlap of coverage with A\&I databases, budget pressures, and lack of associated free-text would make librarians more comfortable in canceling these databases. Also, in 2010, Chen ${ }^{11}$ argued for the cancellation of A\&I databases. Chen reviewed the free availability of journal tables of contents on the web. His general findings were that 94.4 percent of journals in his sample posted their table of contents freely online and concluded that the integration into search engines of journal tables of contents, and in particular GS, which he states can be categorized as a "federated search engine," argues for libraries prioritizing the purchasing of full-text articles over A\&I databases.

In 2011, Garczynski ${ }^{12}$ reported the results of a faculty survey on preferred methods for faculty consultation in a database cutting project. Although there was some disagreement from specific disciplines, the overall preferred approach was for libraries to provide a list of proposed cuts for faculty comment. In 2012, Shapiro ${ }^{13}$ detailed criteria for database cancellations including usage statistics, overlap analysis with other resources, and consideration of political factors such as closed academic programs and faculty consultation.

Since the debut of GS in 2004, there has been extensive discussion in the literature of its place in science and technology academic research and whether it is a companion to A\&I databases or can serve as a substitute for some databases. Complicating this debate is the lack of information from Google as to exactly how GS is constructed and what content it covers. There are also issues with GS's citation counts. ${ }^{14}$ That said, despite librarian concerns about GS's provenance and precision, science librarians know that our users are consulting it exten- 
sively. I will not try to summarize the complete literature on the adequacy of GS versus for-pay Science and Technology bibliographic databases; instead, I will present a few highlights that may relate to my findings. In 2010, Hightower and Caldwell ${ }^{15}$ surveyed science faculty at University of California Santa Cruz on their usage of databases including GS and their preference for keeping journal subscriptions over article databases. Results showed that Web of Science (WoS) was the most heavily used database, at 41.6 percent use; PubMed and Google were in second and third places, at 21.5 percent and 18.7 percent respectively. " $83 \%$ of respondents had used GS and ... of those who had used GS ... 73\% found it useful." For the GS users, 31 percent preferred GS, with 47.5 percent preferring WoS; reasons given for preferring GS included ease of use, speech, and cost (GS is free). Also of note was that " $60.3 \%$ of researchers indicated that they relied most heavily on either WoS or GS and not on a subject-specific database, and that these researchers came from almost every science discipline." Researchers showed a preference for retaining journal subscriptions, at 66 percent, over article databases at 34 percent. On the question of preference for multidisciplinary databases over subjectspecific databases, multidisciplinary databases were preferred 59.9 percent over 32.2 percent for subject-specific databases. In 2011, Kirkwood and Kirkwood ${ }^{16}$ compared searching BIOSIS Preview and GS. Although they had some issues with GS, including implementation of the OR operator and inflated citation counts, they found similar content and could not identify a "clear cut winner." Gray et al. ${ }^{17}$ recommended some degree of continuing scepticism by librarians about relying on GS as a primary research tool in the sciences, while conceding that it has a place in our instruction practices. Their primary concerns are a lack of accountability about how GS works and is constructed as well as issues with quality and accuracy. They do allow that its strength is retrieving open source content as well as material not found on traditional databases. This kind of retrieval is described by Mikki ${ }^{18}$ as GS's "long tail of minor relevant items" not found in bibliographic databases. Mikki found that, for Earth Sciences, 85 percent of the resources found in WoS were also found in GS.

In 2012, Cusker ${ }^{19}$ compared GS and Compendex for engineering research. Cusker found that Compendex performed better, but that, for articles found in Compendex and then searched in GS, GS retrieved an average of 75 percent of the articles. Although GS lacks many of the elements that allow for precision of search and manipulation of results, given that it is free and that students and faculty are comfortable using it, and that the cost of Compendex is in the tens of thousands of dollars for a large institution, Cusker suggested that it was worth considering discontinuing Compendex. Finally, in 2017, Halevi et al. ${ }^{20}$ reviewed the literature comparing GS to Scopus, WoS, and other science databases from 2005 through 2016 to determine if GS was a "suitable source of scientific information and as a source of data for scientific evaluation." Their conclusion was that GS was a powerful tool; however, "caution should be exercised when relying on GS for citations and metrics mainly because it can be easily manipulated and its indexing quality still remains a challenge."

\section{Populations}

Association of Research Libraries (ARL) and Oberlin Group libraries were the populations chosen for this study. ARL is an organization of 125 research libraries at comprehensive, research-intensive institutions in the United States and Canada that share similar research missions, aspirations, and achievements. Only ARL university libraries were included in the survey. Also excluded were libraries with neither a database list nor a searchable database of 
databases, as well as libraries where their list was inaccessible remotely due to being behind a proxy server. Libraries that erected such barriers after the study commenced were also removed. There were 125 ARL libraries in 2010, when the first census was initiated, of which 117 were university libraries. Nine of these were problematic for searching due to the issues mentioned above, so the sample ended up being 108 ARL university libraries. The Oberlin Group is a consortium composed of selective, top-ranked liberal arts college libraries in the United States. Studying the ARL population was a natural choice, as the author worked at an ARL library at the time and the population size was manageable for searching. The Oberlin Group was chosen because it would provide a counterpoint to the higher collections budget libraries found at ARLs and because the author had experience with negotiating an INSPEC consortium while working at an Oberlin Group library in the late nineties. The author had an ongoing interest in how liberal arts college libraries meet the demand for science information with their more limited collections budgets. In 2010, the Oberlin Group membership was 80 libraries. The same restrictions were applied with regard to either the lack of a database list or proxy issues. The Oberlin review ended up including 74 libraries. There has been no need to remove a library from either group since the 2012 scan, and the excluded libraries have not been revisited.

The roster of databases to search was developed based on personal experience from 18 years in science and technology librarianship and some early sampling of 10 major SciTech library database lists. While the roster is not perfect, it includes what are arguably the top one or two comprehensive bibliographic databases in the SciTech disciplines of biology, chemistry, earth sciences, engineering, environmental studies, math, and physics. It should be noted that one SciTech discipline, computer sciences, is not well represented in the group of databases studied, although it is covered by many of the databases. There is not one core/ essential computer-science-only database, and many of the essential databases for computer science are full text, like those from IEEE and ACM, and thus are outside the parameters for this study. Medline/PubMed and AGRICOLA were excluded due to being freely available. Also included were some more specialized indexes such as several of the more specialized Proquest indexes, and the former Wilson Indexes now owned by EBSCO. Comprehensive science databases such as Scopus, WoS, Journal Citation Reports, Current Contents and General Science Index were also included. The complete roster of 21 databases searched can be found in table 1 . There was initially some variation between the rosters for the two populations studied that were (for the most part) standardized in the second year of the census; one unfortunate exception to this standardization was Environment Index, which was included in ARL but not in Oberlin until 2017.

\section{Issues in Database Naming and Configuration}

The census is a study for the presence of the name of a database on a library website's A-Z list. It is not an absolute indicator of the presence or absence of the contents of a specific database at the library in question. For example, with the indexes Applied Science and Technology Index, Biology and Agriculture Index, and General Science Index, the content could be listed on the A-Z lists either separately or not named separately but could still be present as part of an omnibus EBSCO/Wilson product, or they could be listed under both. For comparability, I have chosen only to include the case where the database is explicitly named as a separate entry in the A-Z list. Proquest and EBSCO databases are particularly problematic, because both 


\begin{tabular}{|c|c|}
\hline \multicolumn{2}{|c|}{$\begin{array}{c}\text { TABLE } 1 \\
\text { Database Searched, Accepted Naming Variations for Inclusion and Searching Rules }\end{array}$} \\
\hline Database Name & Accepted Name Variations and Search Rules \\
\hline $\begin{array}{l}\text { Applied Science and Technology Index } \\
\text { (includes Source) }\end{array}$ & $\begin{array}{l}\text { Applied Science and Technology: Abstracts or Source or } \\
\text { Full text or prefix Wilson prefix, if only retrospective version } \\
\text { then not included }\end{array}$ \\
\hline Aquatic Science \& Fisheries Abstracts & $\begin{array}{l}\text { ASFA, any or all of parts 1-4 considered acceptable for } \\
\text { inclusion }\end{array}$ \\
\hline Biological Abstracts & BIOSIS, BIOSIS Previews, BIOSIS Citation Index, WoS prefix \\
\hline Biological Sciences & $\begin{array}{l}\text { Also Life Sciences CSA or Proquest prefixes, Collection } \\
\text { suffix-was not searched } 2010\end{array}$ \\
\hline Biology and Agriculture Index & Biology and Agriculture Abstracts or Plus or Wilson prefix \\
\hline Compendex & Engineering Village \\
\hline Current Contents Connect & Current Contents \\
\hline \multicolumn{2}{|l|}{ Environment Complete } \\
\hline Environment Index & $\begin{array}{l}\text { Not searched } 2010-11 \text { for ARL and not included in Oberlin } \\
\text { list until } 2017 .\end{array}$ \\
\hline $\begin{array}{l}\text { Environmental Science and Pollution } \\
\text { Abstracts }\end{array}$ & $\begin{array}{l}\text { CSA or Proquest prefixes, Environmental Science Collection } \\
\text { suffix }\end{array}$ \\
\hline $\begin{array}{l}\text { General Science Index (General Science } \\
\text { Abstracts, Source) }\end{array}$ & General Science Abstracts, Source, or Fulltext, Wilson prefix \\
\hline \multicolumn{2}{|l|}{ GeoRef } \\
\hline INSPEC & If only retrospective or archive, then not included \\
\hline Journal Citation Reports (includes Incites) & JCR, Incites Journal Citation Reports \\
\hline \multicolumn{2}{|l|}{ MathSciNet } \\
\hline Plant Sciences & CSA or Proquest prefix \\
\hline Reaxys & Beilstein or Crossfire \\
\hline Web of Science & Science Citation Index, Web of Knowledge, WoS or ISI prefix \\
\hline
\end{tabular}

vendors redistribute their content to sell it as various packages ranging from small subsets to large omnibus versions, with even the omnibus versions coming with varying content and subtly different names. These inconsistencies in naming and content led to the exclusion of some databases from the study, in particular the Proquest engineering databases. There are also omnibus science databases that are sold in pieces. Proquest databases Biological Sciences Collections and Environmental Science and Pollutions Abstracts Collections are included in the survey's database roster, although in this case the whole package needed to be named rather than just the parts. There is also an issue in variations in names given to databases (for instance, BIOSIS versus Biological Abstracts or Reaxys vs Crossfire vs Beilstein). Further complication is added by name and ownership changes. Table 1 lists the database naming variations that were considered acceptable for inclusion of a database name in the results during the searching process. As well, some databases are left off library A-Z lists or are named incorrectly. Sometimes it was possible to tell that a database was present, even though named incorrectly, by looking at the URL underlying the name, in which case it was marked as subscribed to. So despite every reasonable effort being made to verify the data collected, because 
the researcher was not authorized to actually access databases at the libraries studied, it is impossible to definitively verify the actual presence, absence, or correct naming of a database.

\section{Method}

Each year, a checklist of the databases and libraries in this study was generated in MS Excel and printed. Google was used to find the library websites, and the author then navigated to the database list and checked by name for each of the databases, including the accepted name variations listed in table 1 . The presence of a database was marked by hand on the spreadsheet. All searches were conducted between August and November each year to avoid calendar and fiscal year cancelation time as much as possible. When data collection for the year was complete, the data was entered into the Excel spreadsheet for that year and then compiled into the ongoing overall spreadsheet compilation of all the data. This overall spreadsheet was then analyzed and, in all cases where a database appeared to be new or no longer was present (assumed cancelled), results were rechecked against the library's A-Z list. All remaining status changes were then rechecked using the Internet Archive Wayback Machine (IAWM) to confirm the previous year's status. Not all previous year statuses could be confirmed in the IAWM. Library websites with a "no robots" tag and some nonstatic A-Z lists (that is to say, many product-generated database A-Z lists, like those from Springshare and Metalib) do not show past year results in the IAWM. If the change could not be verified through IAWM, the next step was to send an email to the library in question to verify the change in status. About 15 such emails were sent each year, and most were answered. Obviously, a study with $~ 3,800$ yes or no responses per year has a lot of room for error, such as missed databases in searching/browsing or misentered data in both the print and electronic spreadsheets. A great deal of effort was made to verify the status of added and/or cancelled databases, but experience has shown errors have been made. As more years of data have been collected, the probability of long-running error is likely to decrease; in the past five years, three long-running errors in holdings have been discovered. That said, it is possible that there are still errors in the data. For the purposes of this publication, only results from 2011 to 2016 are being reported, though data was collected for 2010 and has been collected for 2017 and 2018. The years 2010 and 2017 data were used as error checks on the published data. The 2010-2018 and subsequent data will be included in an open access deposit of this paper's raw data. The 2017-2018 data will be used in follow-up research. It should also be noted that the database list for 2017 was changed due to significant changes in Proquest's database offerings, and Environment Index has been added to the Oberlin Group.

\begin{tabular}{|l|l|l|l|}
\hline \multicolumn{4}{|c|}{ Categories of Databases Studied } \\
\hline Discipline Specific & Comprehensive & Wilson/EBSCO & Proquest \\
\hline - Biological Abstracts & - Current Contents & - Applied Science and & - Aquatic Science and \\
- Compendex & - Journal Citation & Technology Index & Fisheries Abstracts \\
- GeoRef & Reports & - Biology and Agriculture & - Biological Sciences \\
- INSPEC & - Web of Science & Index & - Environmental Science \\
- MathSciNet & - Scopus & - Environment Complete & and Pollution Abstracts \\
- Reaxys & & - Environment Index & - Plant Sciences \\
- SciFinder Scholar & & - General Science Index & - Water Resources \\
\hline
\end{tabular}




\section{Results}

To simplify the reporting and discussion of results, the databases have been divided into four broad-based categories (see table 2).

Tables 3, 6, 11, and 12 summarize the results for all databases from, separately, both ARL university libraries and Oberlin Group libraries. The following results are reported:

- Year: Year census was conducted; 2011 and 2016 holdings data are presented

- \# Holding: Number of libraries that had the database during year indicated, of 108 for ARL and of 74 for Oberlin

- \% with Database: Percentage of the libraries that held the database

- Add: Actual number of schools that added the database between 2012 and 2016

- Canc: Actual number of schools that cancelled the database between 2012 and 2016

- $\Delta$ in \# Holding: Overall drop/increase in number of schools that held the database between 2011 and 2016

- \% $\Delta$ in \# Holding: Overall drop/increase in percentage of the number of schools that held the database between 2011 and 2016

\section{Discipline-specific Databases}

This group includes the databases that, due to their holding unique and essential disciplinespecific content, most SciTech librarians would have traditionally considered the most essential discipline-specific databases comprising a comprehensive science and technology collection (Compendex only being necessary for institutions with an engineering school). MathSciNet and SciFinder Scholar were found at all ARL libraries and neither was cancelled by any ARL library during the study period. Given that some form of access to Chemical Abstracts helps with American Chemical Society undergraduate program accreditation, it seems unlikely it

\begin{tabular}{|c|c|c|c|c|c|c|c|c|c|c|c|c|c|c|}
\hline $\mathrm{Nu}$ & bers of & RL Un & vers & L & aries & and $O$ & $\begin{array}{l}\text { TABLE } 3 \\
\text { rlin Group L }\end{array}$ & ibra & es Hold & g Disc & lin & & fic I & oase \\
\hline & & RL Univer & rsity I & ibrar & ies & & Database & & & berlin $\mathbf{G r}$ & oup L & ibrar & & \\
\hline Year & $\begin{array}{l}\text { \# holding } \\
\text { (of 108) }\end{array}$ & $\begin{array}{l}\% \text { with } \\
\text { database }\end{array}$ & adds & canc & $\begin{array}{l}\Delta \text { in \# } \\
\text { holding }\end{array}$ & $\begin{array}{l}\% \Delta \text { in \# } \\
\text { holding }\end{array}$ & & Year & $\begin{array}{l}\text { \# holding } \\
\text { (of 74) }\end{array}$ & $\begin{array}{l}\% \text { with } \\
\text { database }\end{array}$ & adds & canc & $\begin{array}{l}\% \Delta \text { in \# } \\
\text { holding }\end{array}$ & $\begin{array}{l}\Delta \text { in \# } \\
\text { holding }\end{array}$ \\
\hline 2011 & 98 & 90.7 & 1 & 8 & -7 & 7.1 & Biological & 2011 & 32 & 43.2 & 1 & 4 & 9.4 & -3 \\
\hline 2016 & 91 & 84.3 & & & & & Abstracts & 2016 & 29 & 39.2 & & & & \\
\hline 2011 & 98 & 90.7 & 0 & 8 & -8 & 8.2 & Compendex & 2011 & 9 & 12.2 & 0 & 4 & 44.4 & -4 \\
\hline 2016 & 90 & 83.3 & & & & & & 2016 & 5 & 6.8 & & & & \\
\hline 2011 & 103 & 95.4 & 0 & 3 & -3 & 2.9 & GeoRef & 2011 & 50 & 67.6 & 3 & 3 & 0 & 0 \\
\hline 2016 & 100 & 92.6 & & & & & & 2016 & 50 & 67.6 & & & & \\
\hline 2011 & 87 & 80.6 & 1 & 17 & -16 & 18.4 & INSPEC & 2011 & 22 & 29.7 & 2 & 10 & 36.4 & -8 \\
\hline 2016 & 71 & 65.7 & & & & & & 2016 & 14 & 18.9 & & & & \\
\hline 2011 & 108 & 100.0 & 0 & 0 & 0 & 0 & MathSciNet & 2011 & 67 & 90.5 & 3 & 2 & 1.5 & 1 \\
\hline 2016 & 108 & 100.0 & & & & & & 2016 & 68 & 91.9 & & & & \\
\hline 2011 & 77 & 71.3 & 4 & 4 & 0 & 0 & Reaxys & 2011 & 3 & 4.1 & 2 & 0 & 40 & 2 \\
\hline 2016 & 77 & 71.3 & & & & & & 2016 & 5 & 6.8 & & & & \\
\hline 2011 & 108 & 100.0 & 0 & 0 & 0 & 0 & SciFinder & 2011 & 63 & 85.1 & 4 & 0 & 6 & 4 \\
\hline 2016 & 108 & 100.0 & & & & & Scholar & 2016 & 67 & 90.5 & & & & \\
\hline
\end{tabular}


would, or will in the future, be cancelled. MathSciNet contains a great deal of unique content and is an essential resource for mathematicians; it is also relatively inexpensive compared to most discipline-specific science databases. It should be noted that, throughout this discussion, costs will occasionally be referred to and are based upon the experience of the author, who has worked in science and technology collection development for more than 25 years at five libraries. In the Oberlin Group, both SciFinder Scholar and MathSciNet are the most widely held databases, with SciFinder added at four colleges between 2011 to 2016, an increase from 85.1 percent to 90.5 percent of the group. MathSciNet is the most widely held database in the Oberlin Group, which makes sense given its relative low cost and importance to mathematicians.

Reaxys, a chemistry data/information and A\&I database, though not as widely held at ARL libraries as SciFinder Scholar, did not change in total holding during the study period, though it rose from 77 schools to 81 schools between 2011 and 2015 and then was cancelled at four schools in 2016 (see table 4). It should be noted at this point that 2016 saw far more ARL cancellations than any other year (see table 5). Reaxys, a relatively expensive database, is held by very few Oberlin schools (see tables 3 and 4). GeoRef tends to be one of the less expensive databases in this grouping and is certainly a core database for ARL libraries, being found at 103 libraries in 2011; three schools cancelled it over the study period, with two of those cuts coming in 2016. At Oberlin Group, it held steady at 50 schools - though there was some volatility, with three

\begin{tabular}{|c|c|c|c|c|}
\hline \multicolumn{5}{|c|}{ TABLE 4 } \\
\hline \multicolumn{3}{|c|}{ Reaxys Holdings from 2011-2016 } \\
\hline ARL University & Database & \multicolumn{2}{|c|}{ Oberlin Group } \\
\cline { 1 - 1 } \cline { 4 - 4 } Year & $\begin{array}{c}\text { \# holding } \\
\text { (of 108) }\end{array}$ & & Year & $\begin{array}{c}\text { \# holding } \\
\text { (of 74) }\end{array}$ \\
\hline 2011 & 77 & \multirow{2}{*}{ Reaxys } & 2011 & 3 \\
\hline 2012 & 79 & & 2012 & 4 \\
\hline 2013 & 81 & & 2013 & 5 \\
\hline 2014 & 81 & & 2014 & 5 \\
\hline 2015 & 81 & & 2015 & 5 \\
\hline 2016 & 77 & & 2016 & 5 \\
\hline
\end{tabular}

TABLE 5

Total Number of Cancellations and Additions 2012-16

\begin{tabular}{|l|l|c|c|c|c|c|c|}
\hline \multicolumn{2}{|c|}{} & $\mathbf{1 2}$ & $\mathbf{1 3}$ & $\mathbf{1 4}$ & $\mathbf{1 5}$ & $\mathbf{1 6}$ & Total \\
\hline \multirow{3}{*}{ ARL } & Cancel & 27 & 8 & 18 & 13 & 47 & 113 \\
\cline { 2 - 8 } & Add & 34 & 19 & 33 & 24 & 12 & 122 \\
\hline \multirow{3}{*}{ Oberlin } & Cancel & 14 & 11 & 15 & 3 & 7 & 50 \\
\cline { 2 - 8 } & Add & 12 & 9 & 15 & 5 & 10 & 51 \\
\hline
\end{tabular}
schools cancelling it and three adding.

Three of the core databases saw noteworthy cancellation levels. The physics and engineering database INSPEC was the most heavily cancelled database, going from 87 ARL libraries to 71 and from 22 to 14 at Oberlin Group libraries. Seventeen ARL libraries cancelled it, including 7 during 2016, and only one library added it. Now held by 65.7 percent of ARL libraries, it is questionable whether INSPEC, a relatively expensive database, can still be considered a database that most well-rounded ARL libraries would have as part of a comprehensive subject-oriented database collection, as was once, arguably, the case. It should be noted that several of the libraries that cancelled INSPEC maintained access to their retrospective content (1898-1968, available as a one-time backfile purchase). Whether they will continue to do so, given ongoing maintenance costs for hosting the retrospective content, is an interesting question that is beyond the scope of this study. INSPEC was also the most heavily cancelled 


\begin{tabular}{|c|c|c|c|c|c|c|c|c|c|c|c|c|c|c|}
\hline \multicolumn{15}{|c|}{$\begin{array}{c}\text { TABLE } 6 \\
\text { Comprehensive Databases Summary of Results }\end{array}$} \\
\hline \multicolumn{7}{|c|}{ ARL University Libraries } & \multirow[t]{2}{*}{ Database } & \multicolumn{7}{|c|}{\begin{tabular}{|c|} 
Oberlin Group Libraries \\
\end{tabular}} \\
\hline Year & $\begin{array}{l}\begin{array}{l}\text { \# holding } \\
\text { (of 108) }\end{array} \\
\end{array}$ & \begin{tabular}{|l|}
$\begin{array}{l}\text { \% with } \\
\text { database }\end{array}$ \\
\end{tabular} & adds & canc & \begin{tabular}{|l|}
$\Delta$ in \# \\
holding \\
\end{tabular} & $\begin{array}{l}\% \Delta \text { in \# } \\
\text { holding }\end{array}$ & & Year & \begin{tabular}{|l|}
$\begin{array}{l}\text { \# holding } \\
\text { (of 74) }\end{array}$ \\
\end{tabular} & $\begin{array}{l}\% \text { with } \\
\text { database }\end{array}$ & adds & canc & $\begin{array}{l}\% \Delta \text { in \# } \\
\text { holding }\end{array}$ & $\begin{array}{l}\Delta \text { in \# } \\
\text { holding } \\
\end{array}$ \\
\hline 2011 & 16 & 14.8 & \multirow[t]{2}{*}{33} & \multirow[t]{2}{*}{6} & \multirow[t]{2}{*}{27} & \multirow[t]{2}{*}{62.8} & \multirow{2}{*}{$\begin{array}{l}\text { Current } \\
\text { Contents }\end{array}$} & 2011 & 4 & 5.4 & \multirow[t]{2}{*}{6} & \multirow[t]{2}{*}{0} & \multirow[t]{2}{*}{60} & \multirow[t]{2}{*}{6} \\
\hline 2016 & 43 & 39.8 & & & & & & 2016 & 10 & 13.5 & & & & \\
\hline 2011 & 102 & 94.4 & \multirow[t]{2}{*}{4} & \multirow[t]{2}{*}{0} & \multirow[t]{2}{*}{4} & \multirow[t]{2}{*}{3.8} & \multirow{2}{*}{$\begin{array}{l}\text { Journal } \\
\text { Citation } \\
\text { Reports }\end{array}$} & 2011 & 7 & 9.5 & \multirow[t]{2}{*}{6} & \multirow[t]{2}{*}{1} & \multirow[t]{2}{*}{41.7} & \multirow[t]{2}{*}{5} \\
\hline 2016 & 106 & 98.1 & & & & & & 2016 & 12 & 16.2 & & & & \\
\hline 2011 & 105 & 97.2 & \multirow[t]{2}{*}{2} & \multirow[t]{2}{*}{1} & \multirow[t]{2}{*}{1} & \multirow[t]{2}{*}{0.9} & \multirow{2}{*}{$\begin{array}{l}\text { Web of } \\
\text { Science }\end{array}$} & 2011 & 50 & 67.6 & \multirow[t]{2}{*}{7} & \multirow[t]{2}{*}{5} & \multirow[t]{2}{*}{3.8} & \multirow[t]{2}{*}{2} \\
\hline 2016 & 106 & 98.1 & & & & & & 2016 & 52 & 70.3 & & & & \\
\hline 2011 & 34 & 31.5 & \multirow[t]{2}{*}{36} & \multirow[t]{2}{*}{9} & \multirow[t]{2}{*}{27} & \multirow[t]{2}{*}{44.3} & \multirow[t]{2}{*}{ SCOPUS } & 2011 & 16 & 21.6 & 3 & 7 & 25 & -4 \\
\hline 2016 & 61 & 56.5 & & & & & & 2016 & 12 & 16.2 & & & & \\
\hline
\end{tabular}

Oberlin Group database; with 10 cancellations and only 2 adds, it went from 22 to 14 schools. More study is needed to determine why INSPEC has been so widely targeted for cancellation, although it is likely related to its relatively high price. Potentially, its users in engineering, computer science, and physics may feel that they would rather preserve full-text databases and journal packages and are willing to sacrifice INSPEC given other "adequate" alternatives such as WoS, Scopus, and GS.

Biological Abstracts has seen reductions in both ARL and Oberlin Group libraries. In ARL, the drop was six (6.2\%), from 98 to 91, with seven cancellations and one addition; four of the cancellations occurred in 2016. In the Oberlin Group, Biological Abstracts saw a drop of three $(9.4 \%)$ from 32 to 29 , including four cancellations and one addition. This represented, however, a larger percentage drop in count, 9.4 percent versus 7.1 percent for ARL members. Compendex has also seen substantial cancellation, with ARL holdings dropping by eight from 98 to 90 schools, including five cancellations in 2016. In the Oberlin Group, Compendex saw a similar dramatic drop, going from holdings at nine schools to five. No library in either group added Compendex during the study period. Cusker's 2013 article ${ }^{21}$ on Compendex and GS showed much of Compendex's content is available in GS. The fact of overlap and indeed Cusker's findings may have nudged budget-stressed librarians toward cancellation. One cancellation note found on a database $A-Z$ list during the census suggested Scopus as an alternative.

\section{Comprehensive Databases}

The comprehensive databases group includes databases that cover all of the sciences as well as other disciplines. Current Contents (CC) was included in the study as it was once a relatively heavily used resource in the sciences in its paper form, and the author was curious as to its fate. Initial findings indicated it was no longer

\begin{tabular}{|c|c|c|c|c|}
\hline \multicolumn{5}{|c|}{$\begin{array}{c}\text { TABLE } 7 \\
\text { Current Content Holdings Trends } \\
\text { 2011-2016 }\end{array}$} \\
\hline \multicolumn{2}{|c|}{ ARL University } & \multirow[t]{2}{*}{ Database } & \multicolumn{2}{|c|}{ Oberlin Group } \\
\hline Year & $\begin{array}{l}\text { \# holding } \\
\text { (of 108) }\end{array}$ & & Year & $\begin{array}{c}\text { \# holding } \\
\text { (of 74) }\end{array}$ \\
\hline 2011 & 16 & \multirow{6}{*}{$\begin{array}{l}\text { Current } \\
\text { Contents }\end{array}$} & 2011 & 4 \\
\hline 2012 & 14 & & 2012 & 4 \\
\hline 2013 & 19 & & 2013 & 5 \\
\hline 2014 & 32 & & 2014 & 9 \\
\hline 2015 & 41 & & 2015 & 9 \\
\hline 2016 & 43 & & 2016 & 10 \\
\hline
\end{tabular}


considered to be core, being found in 2011 at only 16 ARL libraries and four Oberlin Group libraries. As table 7 data shows, it dropped in 2012 and then subsequently began a very rapid increase to 43 ARL libraries in 2016 and 10 Oberlin Group libraries (see table 7).

This change can likely be attributed to a special pricing offer from Thomson Reuters in 2013/14 that offered ongoing free access to CC along with a package of other WoS offerings for a one-time fee. It is, however, difficult to say this with any certainty, given the lack of transparency with database pricing and variations of vendors' special offers to libraries.

Web of Science (WoS) is unquestionably still a core database at ARL libraries, with holdings at 106 libraries as of 2016 and two added subscriptions and only one cancellation during the census period. The one cancellation of WoS, at University of Connecticut (UConn), was based on an unpublished study $\mathrm{y}^{22}$ comparing it to SCOPUS, and UConn is the only example in the data set of an ARL library cancelling WoS in favor of maintaining SCOPUS. A personal communication received when sharing some study results on the Listserv STS-L indicates that the University of Utah cancelled WoS in favour of Scopus in December 2009 but, after a faculty outcry, restored it in fall 2010. The only other ARL library not subscribing to WoS is Howard University, which, based on IAWM searching, added Scopus in 2011 and, based on searches back to 2011 in IAWM, does not appear to have had a WoS web-based subscription (there is, however, evidence of Science Citation Index holdings in CD-ROM form in their A-Z list from 2008 to 2011). Oberlin Group holdings of WoS were more volatile, with five cancellations and seven additions. By the end of the study period, WoS was held by 52 (or 70.3\%) of the schools. There is circumstantial evidence in the raw holdings data that some of these cancellations were direct tradeoffs for subscribing to Scopus and some were for choosing not to maintain subscriptions to both; one library did not maintain access to either.

Journal Citation Reports (JCR) was found at 106 of the 108 ARL libraries, including virtually all the libraries subscribing to WoS, and at UConn. The only exception was Dartmouth College Library, which did not show holdings for JCR at any point during the census but does hold WoS. Personal communication indicates they do in fact hold JCR but choose not to include it in their A-Z list. Howard University, which does not subscribe to WoS, also shows no holdings for JCR. In Oberlin Group schools, holdings for JCR are on the rise-but it is still relatively uncommon, with only 12 schools holding it in 2016.

Holdings of Scopus at both ARL and Oberlin Group libraries were quite volatile (see table 8). Scopus reached peak holdings in ARL libraries in 2015 at 66 libraries (rising from 34 libraries in 2011) and in Oberlin Group peaked at 16 libraries in 2013 from 12 libraries in 2011. Eight ARL schools added Scopus during the study period and then dropped it, with six of those cancellations taking place in 2016. Five of the eight were from University of California campuses that had mostly added Scopus in 2014 (see table 9). The ninth school had Scopus in 2011 and cancelled it in 2014. An overlap analysis shows that only two ARLs hold only Scopus, 47 have WoS only, and 59 hold both (see table 10). Within the Oberlin Group, there have been seven cancellations and

\begin{tabular}{|c|c|c|c|c|}
\hline \multicolumn{4}{|c|}{ TABLE 8 } \\
\hline \multicolumn{3}{|c|}{ SCOPUS Holdings Trends 2011-2016 } \\
\hline \multicolumn{2}{|c|}{ ARL University } & Database & \multicolumn{2}{|c|}{ Oberlin Group } \\
Year & $\begin{array}{c}\text { \# holding } \\
\text { (of 108) }\end{array}$ & & Year & $\begin{array}{c}\text { \# holding } \\
\text { (of 74) }\end{array}$ \\
\hline 2011 & 34 & SCOPUS & 2011 & 16 \\
\hline 2012 & 45 & & 2012 & 15 \\
\hline 2013 & 52 & & 2013 & 16 \\
\hline 2014 & 62 & & 2014 & 13 \\
\hline 2015 & 66 & & 2015 & 12 \\
\hline 2016 & 61 & & 2016 & 12 \\
\hline \multirow{nnnn}{nnnn}{} & & & \\
\hline
\end{tabular}




\begin{tabular}{|l|c|c|c|c|c|c|}
\hline TABLE 9 & \multicolumn{7}{|c|}{ Scopus } \\
\hline & University of California Schools Scopus Holdings 2011-16 \\
\hline & $\mathbf{1 1}$ & $\mathbf{1 2}$ & $\mathbf{1 3}$ & $\mathbf{1 4}$ & $\mathbf{1 5}$ & $\mathbf{1 6}$ \\
\hline University of California, Berkeley Library & & & & 1 & 1 & 1 \\
\hline University of California, Davis & & & & 1 & 1 & 1 \\
\hline University of California, Irvine Libraries & & & & 1 & 1 & \\
\hline University of California, Los Angeles & & 1 & 1 & 1 & 1 & \\
\hline University of California, Riverside Libraries & & & & 1 & 1 & \\
\hline University of California, San Diego & & & & 1 & 1 & \\
\hline University of California, Santa Barbara Libraries & & & & 1 & 1 & \\
\hline
\end{tabular}

three adds. One of the cancellations appears to have been a direct tradeoff in favour of adding WoS, with six being at schools that held both WoS and Scopus in 2011. Only two Oberlin schools still held both Scopus and WoS at the end of 2016, with 10 holding Scopus versus 50 choosing WoS over Scopus; 11 libraries have neither. There is clearly more study warranted on why Oberlin Group schools choose Science Citation over Scopus and vice versa. It will also be interesting to watch, after such a rapid rise between 2011 and 2015, whether Scopus levels off or continues to drop as it did in 2016.

\section{Wilson/EBSCO Databases}

EBSCO, like Proquest, serves as a host to many discipline-specific science databases that are nonexclusive to their platform and produced by a third party, such Biological Abstracts, INSPEC, and GeoRef. Also, like Proquest, EBSCO offers a number of discipline-specific science databases that are exclusive to their platform. There are many more such EBSCO exclusive science discipline-specific databases than were included in this study. Chosen for study were the former Wilson Indexes and two EBSCO environmental

\begin{tabular}{|c|c|c|c|c|}
\hline \multicolumn{5}{|c|}{$\begin{array}{c}\text { TABLE } 10 \\
\text { Overlap Analysis for Scopus vs. WoS } \\
\text { for } 2016\end{array}$} \\
\hline & $\begin{array}{l}\text { Scopus } \\
\text { Only }\end{array}$ & $\begin{array}{l}\text { WoS } \\
\text { Only }\end{array}$ & Both & Neither \\
\hline ARL & 2 & 47 & 59 & 0 \\
\hline Oberlin & 9 & 49 & 3 & 13 \\
\hline
\end{tabular}

TABLE 11

Wilson/EBSCO Databases Summary of Results

\begin{tabular}{|c|c|c|c|c|c|c|c|c|c|c|c|c|c|c|}
\hline \multicolumn{7}{|c|}{ ARL University Libraries } & \multirow[b]{2}{*}{ Database } & \multicolumn{7}{|c|}{ Oberlin Group Libraries } \\
\hline Year & \begin{tabular}{|l|} 
\# holding \\
(of 108)
\end{tabular} & \begin{tabular}{|l|}
$\%$ with \\
database
\end{tabular} & adds & canc & \begin{tabular}{|l|}
$\Delta$ in \# \\
holding
\end{tabular} & $\begin{array}{l}\% \Delta \text { in \# } \\
\text { holding }\end{array}$ & & Year & $\begin{array}{l}\text { \# holding } \\
\text { (of 74) }\end{array}$ & $\begin{array}{l}\% \text { with } \\
\text { database }\end{array}$ & adds & canc & $\begin{array}{l}\% \Delta \text { in \# } \\
\text { holding }\end{array}$ & $\begin{array}{l}\Delta \text { in \# } \\
\text { holding }\end{array}$ \\
\hline 2011 & 32 & 29.6 & \multirow{2}{*}{10} & \multirow{2}{*}{14} & \multirow{2}{*}{-4} & \multirow{2}{*}{12.5} & \multirow{2}{*}{$\begin{array}{l}\text { Applied Science and } \\
\text { Technology Index }\end{array}$} & 2011 & 15 & 20.3 & \multirow{2}{*}{2} & \multirow{2}{*}{4} & \multirow{2}{*}{13.3} & \multirow{2}{*}{-2} \\
\hline 2016 & 28 & 25.9 & & & & & & 2016 & 13 & 17.6 & & & & \\
\hline 2011 & 17 & 15.7 & \multirow{2}{*}{2} & \multirow{2}{*}{6} & \multirow{2}{*}{-4} & \multirow{2}{*}{23.5} & \multirow{2}{*}{$\begin{array}{c}\text { Biology and } \\
\text { Agriculture Index }\end{array}$} & 2011 & 11 & 14.9 & \multirow{2}{*}{1} & \multirow{2}{*}{2} & \multirow{2}{*}{9.1} & \multirow{2}{*}{-1} \\
\hline 2016 & 13 & 12.0 & & & & & & 2016 & 10 & 13.5 & & & & \\
\hline 2011 & 24 & 22.2 & \multirow{2}{*}{9} & \multirow{2}{*}{0} & \multirow{2}{*}{9} & \multirow{2}{*}{27.3} & \multirow{2}{*}{$\begin{array}{c}\text { Environment } \\
\text { Complete }\end{array}$} & 2011 & 22 & 29.7 & \multirow{2}{*}{3} & \multirow{2}{*}{1} & \multirow{2}{*}{8.3} & \multirow{2}{*}{2} \\
\hline 2016 & 33 & 30.6 & & & & & & 2016 & 24 & 32.4 & & & & \\
\hline 2012 & 13 & 12.0 & \multirow{2}{*}{2} & \multirow{2}{*}{2} & \multirow{2}{*}{0} & \multirow{2}{*}{0} & \multirow{2}{*}{ Environment Index } & & & & & & & \\
\hline 2016 & 13 & 12.0 & & & & & & & & & & & & \\
\hline 2011 & 30 & 27.8 & \multirow{2}{*}{2} & 6 & 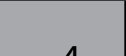 & 127 & General Science & 2011 & 25 & 33.8 & 0 & 6 & 21 & 6 \\
\hline 2016 & 26 & 24.1 & & 0 & -4 & 13.3 & Index & 2016 & 19 & 25.7 & 0 & 0 & 24 & -0 \\
\hline
\end{tabular}


studies databases, a discipline that does not have any major non-Proquest/EBSCO exclusive subject-specific database. Environment Complete was found at 33 ARL libraries at the end of 2016, an increase of nine from 2011 with no cancellations; Environment Index was found at 13 ARL libraries in both 2012 and 2016 with two cancellations and two adds during that period. There was no overlap between the two databases in ARL library holdings. In Oberlin Group libraries, it went from 22 in 2012 to 24 in 2016 with one cancellation and three adds. Environment Index was not studied at Oberlin Group libraries during the study but has been added for 2017.

The holdings information about the former Wilson databases, as discussed below, is complicated by the naming variations for Applied Science and Technology Index, Biology and Agriculture Index, and General Science Index. For instance, Applied Science and Technology, is currently sold under a number of different names with varying levels of indexing and full text as well as the content being included in a number of omnibus packages. There's also a separate retrospective version that was not counted for this study. It should be noted that these databases are also often frequently included in state/provincial or other types of consortial packages, so it is possible they are not being directly paid for by the libraries that show holdings. Holdings of Applied Science and Technology Index (AS\&T), Biology and Agriculture Index, and General Science Index declined between 2011 and 2016. Applied Science and Technology Index was particularly volatile at ARL schools, with 10 additions and 14 cancellations. The net change went from 32 to 28 libraries. At Oberlin Group libraries, holdings of AS\&T fell from 15 to 13, with four cancellations and two additions. General Science dropped by four at ARL libraries from 30 to 26, with six cancellations and two additions; at Oberlin Group libraries the decline was 25 to 19, with six cancellations and no additions. Biology and Agricultural Index is the least held in both groups, going from 17 in 2011 to 13 in 2016 in ARL libraries, with six cancellations and two additions. Among Oberlin Group libraries, there was a net loss of one subscription from 11 to 10, with two cancellations and one addition. The former Wilson databases are certainly no longer the essential databases they once were, ranging from being held at 12 percent to 25.9 percent of the libraries studied. Further study is needed to examine why libraries are still holding onto these databases and whether they are separately subscribed to in all the libraries whose A-Z lists include them, or if they are part of larger packages and the libraries are also listing them separately or if they are part of consortial packages not directly paid for by the individual libraries.

\section{Proquest Databases}

The Proquest databases studied are all former Cambridge Scientific Abstracts products. In the case of Biological Sciences and Environmental Science and Pollution Abstracts, they are broad discipline-based databases composed of a number of smaller intradisciplinary specialized databases. The three intradisciplinary specialized databases studied-Aquatic Science and Fisheries Abstracts (ASFA), Plant Sciences, and Water Resources - were sold as both parts of larger packages as well as separately. The three intradisciplinary specialized databases are now available as part of newly renamed larger packages with ASFA being sold as part of a larger new collection; Earth, Atmospheric, \& Aquatic Science Database, and Plant Sciences being part of Biological Science Database and Water Resources being part of both Earth, Atmospheric, \& Aquatic Science Database and Environmental Science and Pollution Abstracts (renamed Agricultural \& Environmental Science Database for 2017). At least ASFA is still 


\begin{tabular}{|c|c|c|c|c|c|c|c|c|c|c|c|c|c|c|}
\hline \multicolumn{15}{|c|}{$\begin{array}{c}\text { TABLE } 12 \\
\text { ProQuest Databases Summary of Results }\end{array}$} \\
\hline \multicolumn{7}{|c|}{ ARL University Libraries } & \multirow[t]{2}{*}{ Database } & \multicolumn{7}{|c|}{ Oberlin Group Libraries } \\
\hline Year & $\begin{array}{l}\text { \# holding } \\
\text { (of 108) }\end{array}$ & \begin{tabular}{|l|}
$\%$ with \\
database
\end{tabular} & adds & canc & \begin{tabular}{|l}
$\Delta$ in \# \\
holding \\
\end{tabular} & $\begin{array}{l}\% \Delta \text { in \# } \\
\text { holding }\end{array}$ & & Year & \begin{tabular}{|l}
$\begin{array}{l}\text { \# holding } \\
\text { (of 74) }\end{array}$ \\
\end{tabular} & \begin{tabular}{|l|}
$\%$ with \\
database
\end{tabular} & adds & canc & $\begin{array}{l}\% \Delta \text { in \# } \\
\text { holding } \\
\end{array}$ & $\begin{array}{l}\Delta \text { in \# } \\
\text { holding } \\
\end{array}$ \\
\hline 2011 & 61 & 56.5 & \multirow{2}{*}{1} & \multirow{2}{*}{10} & \multirow{2}{*}{-9} & \multirow{2}{*}{14.8} & \multirow{2}{*}{$\begin{array}{l}\text { Aquatic Science \& } \\
\text { Fisheries Abstracts }\end{array}$} & 2011 & 7 & 9.5 & \multirow{2}{*}{1} & \multirow{2}{*}{0} & \multirow{2}{*}{12.5} & \multirow{2}{*}{1} \\
\hline 2016 & 52 & 48.1 & & & & & & 2016 & 8 & 10.8 & & & & \\
\hline 2011 & 27 & 25.0 & \multirow{2}{*}{3} & \multirow{2}{*}{4} & \multirow{2}{*}{-1} & \multirow{2}{*}{3.7} & \multirow{2}{*}{$\begin{array}{l}\text { Biological Sciences } \\
\quad \text { (ProQuest) }\end{array}$} & 2011 & 15 & 20.3 & \multirow{2}{*}{2} & \multirow{2}{*}{1} & \multirow{2}{*}{6.2} & \multirow{2}{*}{1} \\
\hline 2016 & 26 & 24.1 & & & & & & 2016 & 16 & 21.6 & & & & \\
\hline 2011 & 50 & 46.3 & \multirow[b]{2}{*}{5} & \multirow[b]{2}{*}{3} & \multirow[b]{2}{*}{2} & \multirow[b]{2}{*}{3.8} & \multirow{2}{*}{$\begin{array}{c}\text { Environmental } \\
\text { Science and } \\
\text { Pollution Abstracts }\end{array}$} & 2011 & 10 & 13.5 & \multirow[b]{2}{*}{5} & \multirow[b]{2}{*}{0} & \multirow{2}{*}{33.3} & \multirow[b]{2}{*}{5} \\
\hline 2016 & 52 & 48.1 & & & & & & 2016 & 15 & 20.3 & & & & \\
\hline 2011 & 22 & 20.4 & \multirow{2}{*}{2} & \multirow{2}{*}{5} & \multirow{2}{*}{-3} & \multirow{2}{*}{13.6} & Olantcrionsest & 2011 & 4 & 5.4 & 0 & 0 & 0 & 0 \\
\hline 2016 & 19 & 17.6 & & & & & Plant sciences & 2016 & 4 & 5.4 & 0 & 0 & 0 & 0 \\
\hline 2011 & 48 & 44.4 & & 0 & 3 & 62 & Wator Dosourcer & 2011 & 4 & 5.4 & 0 & 0 & 0 & 0 \\
\hline 2016 & 45 & 41.7 & 5 & 8 & -3 & 0.2 & valer nesources & 2016 & 4 & 5.4 & 0 & 0 & 0 & 0 \\
\hline
\end{tabular}

available as a separate product. Proquest has further consolidated these larger databases into several omni-databases, Natural Science Collection and SciTech Premium Collection with the former incorporating their engineering products. The database list searched has been adjusted to include these collections for the 2017 census and future data collection.

Data in table 12 shows that Biological Science Database is not an essential database to hold in either group, with only 26 ARL libraries holding it in 2016, a drop of one from 2011, which represents three additions and four cancellations. In Oberlin Group libraries, it went from 15 libraries to 16 with one cancellation and two additions. A 2016 overlap analysis at ARL libraries (see table 13) among the three biology databases in the study finds that Biological Abstracts is the dominant biology database, with just five schools holding only Biological Sciences and none relying only on Biological and Agricultural Index; 11 schools have no biological science database. In Oberlin Group libraries, Biology Abstracts is also dominant; however, 19 schools do not have Biological Abstracts and instead rely on Biological Sciences or Biology and Agriculture Index (or both). There are 26 schools with no biology database at all.

As table 12 indicates, Environmental Science and Pollution Abstracts is held at 52 ARL libraries, an increase of two representing five additions and three cancellations. At Oberlin Group libraries, it increased from 10 schools to 15, with five adds and no cancellations. The 2016 overlap analysis in table 14 shows that Environmental Science and Pollution Abstracts is the most widely held environmental sciences database at ARL libraries in 2016, while Environment Complete is held most widely at Oberlin Group libraries.

\begin{tabular}{|c|c|c|c|c|c|c|c|c|}
\hline \multicolumn{9}{|c|}{$\begin{array}{l}\text { TABLE } 13 \\
\text { Overlap Analysis of Holdings of Biological Abstracts (Bio Abs), Biological Sciences (Bio Sci) } \\
\text { And Biology and Agriculture Index (Bio-Ag) in } 2016\end{array}$} \\
\hline & $\begin{array}{l}\text { Bio Abs } \\
\text { Only }\end{array}$ & $\begin{array}{l}\text { Bio Sci } \\
\text { Only }\end{array}$ & $\begin{array}{l}\text { Bio-Ag } \\
\text { only }\end{array}$ & $\begin{array}{l}\text { Bio Abs \& } \\
\text { Bio Sci }\end{array}$ & $\begin{array}{l}\text { Bio Abs \& } \\
\text { Bio-Ag }\end{array}$ & $\begin{array}{l}\text { Bio Sci \& } \\
\text { Bio-Ag }\end{array}$ & All 3 & None \\
\hline ARL & 62 & 5 & 1 & 15 & 7 & 0 & 5 & 11 \\
\hline Oberlin & 23 & 12 & 6 & 3 & 3 & 1 & 0 & 26 \\
\hline
\end{tabular}




\section{TABLE 14}

Overlap Analysis of Proquest's Environmental Science and Pollution Abstracts (Env \& Poll Abs) versus EBSCOs Environment Complete (Env Comp) or Environment Index (Env Ind) in 2016 (note Environment Index was not checked for at Oberlin Group Libraries)

\begin{tabular}{|l|c|c|c|c|}
\hline & Env \& Poll Abs only & Either Env Comp or Env Ind only & Both & None \\
\hline ARL & 35 & 29 & 17 & 27 \\
\hline Oberlin & 8 & 17 & 7 & 42 \\
\hline
\end{tabular}

Of the three Proquest intradisciplinary specialized databases surveyed, ASFA was the most widely held, with 52 ARL libraries holding at least one part of ASFA in 2016. This is a decrease of nine, with one addition and 10 cancellations; five of those cancellations occurred in 2016. At Oberlin Group libraries, ASFA went from seven schools to eight, with one addition and no cancellations. Water Resources went down by three from 48 ARL libraries in 2011 to 45 in 2016, with five additions and eight cancellations; in Oberlin Group libraries it stayed steady at four libraries, with no additions or cancellations. Plant Sciences went down by three from 22 ARL libraries in 2011 to 19 in 2016, with two additions and five cancellations. In the Oberlin Group libraries, there were no additions or cancellations to the holdings of four libraries. With the exception of ASFA at ARL, there were few cuts of these subscriptions.

\section{Discussion}

Before discussing the results further, the author again must point out that the study results may contain errors, though much effort was employed to verify results. With approximately 30,000 manual checks for the presence of databases in A-Z lists on library websites along with the accuracy issues with these lists, database naming issues, and manual recording and manipulation of the data, misattributions of holdings have occurred. A check with publishers on their holdings would likely produce subtly different results. The author is, however, quite confident that the trends shown are real.

The results of this longitudinal census of SciTech databases at ARL and Oberlin Group libraries begin to answer some of the questions this study sought to answer and provide a previously unavailable picture of the SciTech database holdings of the major research libraries in North America as well as liberal arts college libraries of the United States. It also raised a new area to be investigated. How do Oberlin Group libraries cover the SciTech disciplines in their holdings? Fifteen percent have neither WoS nor Scopus, 35 percent have no major biology database, and 54 percent do not have any of the major environmental science databases studied. Another significant surprise in the results was "database volatility"; the number of additions versus cancellations of databases in a given year (see table 5). It was certainly unexpected that between 2011 and 2015 there were far more new databases added than cancelled in ARL (66 cancellations versus 110 additions), though this was largely because of the substantial growth of holdings for Current Contents and Scopus. That said, there was still a fair amount of volatility additions and cancellations in many databases, the greatest being with Applied Science and Technology Index and Scopus in ARL libraries (see tables 11 and 6) and Scopus and WoS in Oberlin Group libraries (see table 6). Database volatility and reasons why it is happening, particularly with Applied Science and Technology Index, are areas that the author wishes to look into further. Also of note were the very significant cancellation seen in ARL libraries in 2016. Whether this was an anomaly or the 
start of a trend, and what factors warranted this many cancellations in one year, is worthy of investigation.

Another unexpected result of the study is the rapid growth, and occasional decline, of Scopus at both ARL and Oberlin Group libraries. Table 15 documents the changes in holdings for both WoS and Scopus and, unlike table 6, includes the unverified data from 2010 as well as the not yet double-verified data from 2017. Though it should be viewed with caution, it indicates that the growth in Scopus holdings has been even more spectacular than the more reliable 2011-2016 data. WoS is still clearly the gold standard for comprehensive science databases at ARL libraries. However, Scopus is competing and is clearly seen by many as an important complement to WoS. WoS is also dominant at Oberlin Group libraries, though slightly less so than at ARL. It will be interesting to see if more libraries are forced to choose between these resources, as did University of Connecticut and as did, it appears, some Oberlin Group libraries.

As to the initial questions posed, the cancellations seen across ARL libraries with Biological Abstracts (-6), Compendex (-8) and in particular INSPEC (-16) show that some ARL libraries are indeed choosing to cancel some of their core SciTech databases. The results show that this is also the case at Oberlin Group libraries. Other core SciTech databases have not seen such cancellations, so far-in particular MathSciNet and SciFinder Scholar with no cancellations and GeoRef with only three cancellations in ARL libraries. The former Wilson, now EBSCO science, indexes are in decline and are not held by many ARL or Oberlin Group libraries. As of 2016, the highest share any has is 26 percent of ARL's holding Applied Science and Technology Index. Biology and Agriculture Index has the lowest holdings, with 12 percent of ARL

\begin{tabular}{|c|c|c|c|c|c|c|c|c|c|c|}
\hline \multicolumn{11}{|c|}{$\begin{array}{l}\text { TABLE } 15 \\
\text { Scopus and WoS Holdings at ARL and Oberlin Group Libraries with “Unverified” } 2010 \text { and } \\
2017 \text { Data }\end{array}$} \\
\hline \multicolumn{5}{|c|}{ ARL University Libraries } & \multirow[b]{2}{*}{ Database } & \multicolumn{5}{|c|}{ Oberlin Group Libraries } \\
\hline Year & $\begin{array}{l}\text { \# holding } \\
\text { (of 108) }\end{array}$ & \begin{tabular}{|l|}
$\begin{array}{l}\% \text { with } \\
\text { database }\end{array}$ \\
\end{tabular} & \begin{tabular}{|l|}
$\Delta$ in \# \\
holding \\
\end{tabular} & $\begin{array}{l}\% \Delta \text { in \# } \\
\text { holding }\end{array}$ & & Year & \begin{tabular}{|l|} 
\# holding \\
(of 74)
\end{tabular} & \begin{tabular}{|l|}
$\begin{array}{l}\% \text { with } \\
\text { database }\end{array}$ \\
\end{tabular} & $\begin{array}{l}\Delta \text { in \# } \\
\text { holding } \\
\end{array}$ & $\begin{array}{l}\% \Delta \text { in \# } \\
\text { holding }\end{array}$ \\
\hline 2010 & 105 & 97.2 & \multirow[t]{8}{*}{1} & \multirow[t]{8}{*}{0.9} & \multirow{8}{*}{$\begin{array}{l}\text { Web of } \\
\text { Science }\end{array}$} & 2010 & 49 & 66.2 & \multirow[t]{8}{*}{2} & \multirow[t]{8}{*}{3.8} \\
\hline 2011 & 105 & 97.2 & & & & 2011 & 50 & 67.6 & & \\
\hline 2012 & 105 & 97.2 & & & & 2012 & 53 & 71.6 & & \\
\hline 2013 & 105 & 97.2 & & & & 2013 & 51 & 68.9 & & \\
\hline 2014 & 105 & 97.2 & & & & 2014 & 50 & 67.6 & & \\
\hline 2015 & 106 & 98.1 & & & & 2015 & 52 & 70.3 & & \\
\hline 2016 & 106 & 98.1 & & & & 2016 & 52 & 70.3 & & \\
\hline 2017 & 106 & 98.1 & & & & 2017 & 51 & 68.9 & & \\
\hline 2010 & 26 & 24.1 & \multirow[t]{8}{*}{37} & \multirow[t]{8}{*}{58.7} & \multirow[t]{8}{*}{ SCOPUS } & 2010 & 10 & 13.5 & \multirow[t]{8}{*}{2} & \multirow[t]{8}{*}{17.7} \\
\hline 2011 & 34 & 31.5 & & & & 2011 & 16 & 21.6 & & \\
\hline 2012 & 45 & 41.7 & & & & 2012 & 15 & 20.3 & & \\
\hline 2013 & 52 & 48.1 & & & & 2013 & 16 & 21.6 & & \\
\hline 2014 & 62 & 57.4 & & & & 2014 & 13 & 17.6 & & \\
\hline 2015 & 66 & 61.1 & & & & 2015 & 12 & 16.2 & & \\
\hline 2016 & 61 & 56.5 & & & & 2016 & 12 & 16.2 & & \\
\hline 2017 & 63 & 58.3 & & & & 2017 & 12 & 16.2 & & \\
\hline
\end{tabular}


libraries indicating a subscription. Whether their content is still part of omnibus product or is being purchased consortially is an unanswered question. The two discipline-level Proquest databases studied held pretty much even with Biological Sciences mostly being a companion to Biological Abstracts at ARL libraries, where only five libraries held Biological Science but not Biological Abstracts. At Oberlin Group libraries, Biological Sciences is more of a competitor for Biological Abstracts, albeit with about half the libraries with Biological Sciences also holding Biological Abstracts. For environmental sciences, where there are a lot of databases available besides the three surveyed, it appears that Proquest's Environmental Sciences and Pollution Abstracts is the dominant player at ARL, whereas the EBSCO products are dominant at Oberlin Group libraries. Holdings for the smaller intradisciplinary products from Proquest were mostly in the mid-range at ARL schools, and all saw declines. At Oberlin schools, they were not at all widely held, but those holdings remained pretty steady. These low levels of holdings may have played into the 2017 changes Proquest has made in their database product line, and it will be interesting to see what happens now that Proquest has consolidated these products and also created broader science and SciTech packages.

\section{Summary of Limitations}

As indicated throughout the article, the study method includes a number of potential sources for error when it comes to indicating the absolute absence or presence of a database on a library database list, beyond the central premise that this is a study for the presence or absence of a database by name on a library database list. Every effort has been made to address these issues; however, they should be acknowledged. In summary:

- Author error during annual census: There are $~ 3,800$ manual searches/year, such as misentering or misreading presence or absence of database, as well as transcription errors while working with spreadsheets. These are addressed through verification of changes in holding status and having check years on either side of the years documented in this article.

- Accuracy of database lists and the author's interpretation of them, in particular with some of the EBSCO and Proquest databases. With so many similarly named variations on these databases (in particular environmental databases) and with libraries not always accurately/fully identifying/naming a database in their lists, it is possible that databases have been misattributed. This is addressed, as much as possible, through consistent rules on naming variations and communication with libraries when there is a change in status for such a database.

- Accuracy of library database lists, do they name all their databases held? This is primarily an issue for the Proquest and EBSCO databases though it could also be an issue with some of the other databases studied. There are a few cases where upon inquiry the library did hold a database that they did not list, or where they assumed holding the database was implied by another named holding, or where the name used was not one I would have anticipated. The former Wilson databases studied and some of the Proquest databases may not be separately named in the database list at some schools but may still be present as part of larger packages. Both these issues are dealt with, as much as possible, through consistent rules for naming.

- Though not a source of error, it should be noted that the samples chosen may not be indicative of the wider database market. Other than Canada in ARL, there is no interna- 
tional presence and both of the groups tend to be among the most well-funded libraries in the US and Canada.

\section{Future Research}

The results of this work give a broad outline of current holdings of a number of important science databases and begin to document changes in holding patterns over time; but, in the case of specific cancellations and additions, the results do not yet illuminate the processes and reasoning behind the choices being made. The results from the discipline-specific and comprehensive database groupings are of the most long-term interest. Though several databases have seen significant growth, Scopus in particular, there are clearly more databases that have seen declines in their occurrence on database A-Z lists. Of particular interest for follow-up are the substantial cuts made to INSPEC, 16 for ARL and eight in Oberlin, along with the unexpected Compendex cuts, eight for ARL libraries, including five in 2016. Did these schools have engineering programs, and, for those that do, what is now the primary recommended source for exploring the engineering and physics literature? Although less dramatic, six cuts for ARL and three for Oberlin, the cuts to Biological Abstracts were also of note. Some initial conclusions can be suggested regarding the cancellations in this group: they tend to be the more expensive science databases that lack the additional unique added value functions of the less cancelled expensive discipline-specific databases, in particular access to chemical information (in other words, SciFinder and Reaxys). The less expensive specialized science databases such as MathSciNet and GeoRef did not see notable declines. The analysis also cannot directly address the influence of Google Scholar on decision making nor the influence of the body of literature comparing Google Scholar to A\&I products. To better understand and document the thinking behind targeting these specific database cancellations, it will be necessary to survey libraries and ask about the reasoning and processes behind them. To accomplish this, an additional step will be added to annual data collection process with a brief survey sent to all libraries with cancellations and additions from the discipline-specific and comprehensive database groups focusing on the tradeoffs being made, the hows and whys of the cancellations and additions and, in particular, the influence of comprehensive databases and Google Scholar on decision making. This survey will also allow for a more detailed analysis of choices being made with regard to holdings of the major comprehensive databases WoS and SCOPUS, both of which saw some volatility during the period studied (SCOPUS in particular, WoS only in the Oberlin Group).

With regard to the old Wilson, now EBSCO, science databases, they are clearly not the universal science library presence they once were. None of the three are at more than 26 percent of the groups studied, and all saw declines in holdings. However, these databases are difficult to draw wider conclusions about due to the naming issues and whether the data from these products are still available to the library in other EBSCO products. Though these databases will remain in the annual checklist for now, no further research is planned. The Proquest products present similar challenges with naming and omnibus products. There was clearly a small decline in the presence of their more specialized databases on the ARL database list, which may be a reason for Proquest's remix of their science and technology collections. Holdings for the broader discipline-based Proquest databases, Biological Science and Environmental Science and Pollution Abstracts (now renamed), held fairly even. Libraries with future cancellations and additions for these two databases will be included in the survey mentioned above. 
Sharing the data set and the holdings detailed, with the acknowledgment of the limitations of the data set, will allow for more detailed analysis of possible holding patterns of the databases and institutional groupings surveyed. This analysis of the data does not answer the questions about the choice between relying on comprehensive databases rather than discipline-oriented databases. A more detailed analysis of the individual holdings found in the data to be shared may tease out any answers that are there to be found. Related to this are questions raised about science and technology coverage at Oberlin Group libraries that could come from a more detailed analysis of the holdings data.

\section{Conclusion}

This research, despite the stated limitations, provides a previously unavailable picture of current holdings status of a number of science databases that have long been a part of science librarianship. The results across both ARL and Oberlin Group libraries begin to show some support for Wagner's $2009^{23}$ predictions regarding an anticipated decline for nonadded value A\&I services, with notable dropoffs seen in the holdings for INSPEC, BIOSIS, Compendex, the three former Wilson A\&I indexes, and the smaller Proquest databases at ARL libraries. In addition, the declines seen in INSPEC and Compendex support Tucci's more specific 2010 prediction ${ }^{24}$ of declines for the physical sciences and engineering A\&I databases. The data set, as it continues to grow, will provide more evidence as to whether these trends are real. The results do not answer any questions regarding the role of Google Scholar on cancellation decisions or the impact of the library literature that compares A\&I products such as INSPEC, Compendex, and BIOSIS to Google Scholar on these decisions. Also unknown is the impact of the substantial growth of SCOPUS holdings upon other database retention decisions. Though, again, as the data set grows, along with the planned associated cancellation questions, it may be possible to get a better picture of both the thinking behind the cuts and the connection of Google Scholar and multidisciplinary databases, in particular WoS and SCOPUS, to these cuts. Practical benefits of this research include that science and collections librarians will now have a source to quickly and easily benchmark local science database holdings with peer libraries from both ARL and Oberlin Group libraries. In addition to surfacing evidence of peer practice for librarians facing difficult cancellation decisions, the data can also be used to make the case for the addition of a database held by peer libraries. As libraries' budgets purchasing power continues to decline, changes are made to improve Google Scholar, and the A\&I services surveyed, this study will continue and evolve.

\section{Data}

Data from this study can be found at https://doi.org/10.7939/DVN/JDNPNC.

\section{Acknowledgments}

The author would like to thank the anonymous reviewers and Margaret Law for their valuable suggestions and proofreading. The author gratefully acknowledges the contributions of Deborah Blecic and Stephen Wiberley in the conception of and follow-through of this study. 


\section{Notes}

1. Faye A. Chadwell, “What's Next for Collection Management and Managers?" Collection Management 34, no. 1 (2009): 3-18, https://doi.org/10.1080/01462671003620199.

2. Chadwell, "What's Next for Collection Management and Managers?"

3. Marilyn L. Williamson, "Seven Years of \{Serials\} Cancellations at Georgia Tech," Serials Librarian 9, no. 3 (1985): 103-14, https://doi.org/10.1300/J123v09n03_10.

4. Tina E. Chrzastowski and Karen A. Schmidt, "Surveying the Damage: Academic Library Serial Cancellations 1987-88 through 1989-90," College and Research Libraries 54, no. 2 (March 1993): 93-102, https://doi.org/10.5860/ crl_54_02_93.

5. Tina E. Chrzastowski and Karen A. Schmidt, "Collections at Risk: Revisiting Serial Cancellations in Academic Libraries," College and Research Libraries 57, no. 4 (July 1996): 351-64, https://doi.org/10.5860/crl_57_04_351.

6. Tina E. Chrzastowski and Karen A. Schmidt, "The Serials Cancellation Crisis: National Trends in Academic Library Serial Collections," Library Acquisitions: Practice $\mathcal{E}$ Theory 21, no. 4 (1997): 431-43, https://doi.org/10.1016/ S0364-6408(97)00071-9.

7. Tina E. Chrzastowski, "National Trends in Academic Chemistry Serial Collections, 1992-1994," Science \& Technology Libraries 16, no. 3/4 (1998): 191-207, https://doi.org/10.1300/J122v16n03_12.

8. Norman Oder, "ARL Budget Roundup: Large Academic Libraries Face Cuts in Collections, Staff, Hours," Library Journal (Apr. 29, 2009), available online at http://j.libraryjournal.com/2009/04/budgets-funding/arl-budgetroundup-large-academic-libraries-face-cuts-in-collections-staff-hours/ [accessed 12 November 2017].

9. A. Ben Wagner, "A\&I, Full Text, and Open Access: Prophecy from the Trenches," Learned Publishing 22, no. 1 (Jan. 2009): 73-74, https://doi.org/10.1087/095315108X378820.

10. Valerie Tucci, "Are A \& I Services in a Death Spiral?" Issues in Science \& Technology Librarianship, no. 61 (Spring 2010), https://doi.org/10.5062/F4ZP4419.

11. Xiaotian Chen, "The Declining Value of Subscription-Based Abstracting and Indexing Services in the New Knowledge Dissemination Era," Serials Review 36, no. 2 (2010): 79-85, https://doi.org/10.1080/00987913.2010 .10765288 .

12. Joyce Garczynski, “Making the Cut: Do Faculty Want to Be Involved in Library Database Cancellations?” Practical Academic Librarianship: The International Journal of the SLA Academic Division 1, no. 1 (2011): 16-27.

13. Steven Shapiro, "Database Cancellation: The Hows and Whys," Journal of Electronic Resources Librarianship 24, no. 2 (2012): 154-56, https://doi.org/10.1080/1941126x.2012.684564.

14. Péter Jacsó, "Google Scholar: The Pros and the Cons," Online Information Review 29, no. 2 (2005): 208-14, https://doi.org/10.1108/14684520510598066.

15. Christy Hightower and Christy Caldwell, "Shifting Sands: Science Researchers on Google Scholar, Web of Science, and PubMed, with Implications for Library Collections Budgets," Issues in Science and Technology Librarianship, no. 63 (Fall 2010), https://doi.org/10.5062/F4V40S4J.

16. Hal P. Kirkwood and Monica C. Kirkwood, "Researching the Life Sciences: BIOSIS Previews and Google Scholar," Online, 35 no. 3 (May/June 2011) 24-28.

17. Jerry E. Gray et al., "Scholarish: Google Scholar and its Value to the Sciences," Issues in Science and Technology Librarianship, no. 70 (Summer 2012), https://doi.org/10.5062/F4MK69T9.

18. Susanne Mikki, "Comparing Google Scholar and ISI Web of Science for Earth Sciences," Scientometrics 82, no. 2 (2010): 321-31.

19. Jeremy Cusker, "Elsevier Compendex and Google Scholar: A Quantitative Comparison of Two Resources for Engineering Research and an Update to Prior Comparisons," Journal of Academic Librarianship 39, no. 3 (May 2013): 241-43, https://doi.org/10.1016/j.acalib.2013.02.001.

20. Gali Halevi, Henk Moed, and Judit Bar-Ilan, "Suitability of Google Scholar as a Source of Scientific Information and as a Source of Data for Scientific Evaluation-Review of the Literature," Journal of Informetrics 11, no. 3 (Aug. 2017): 823-34, https://doi.org/10.1016/j.joi.2017.06.005.

21. Cusker, "Elsevier Compendex and Google Scholar."

22. Galadriel Chilton, Dawn Cadogan Arta Dobbs, Alice Fairfield, Joelle Thomas, and Elisabeth Umpleby, "Massive Analysis Project: Scopus, Web of Science, and Google Scholar" (2015), available online at http://alamw15. ala.org/files/alamw15/Chilton_Scopus\%20v\%20Web\%20of\%20Science.pdf [accessed 31 May 2010]

23. Wagner, "A\&I, Full Text, and Open Access."

24. Tucci, "Are A \& I Services in a Death Spiral?" 